University of Wollongong

Research Online

Faculty of Engineering and Information

Faculty of Engineering and Information

Sciences - Papers: Part A

Sciences

$1-1-2015$

Scaling control during membrane distillation of coal seam gas reverse osmosis brine

Hung C. Duong

University of Wollongong, chd581@uowmail.edu.au

Stephen Gray

Victoria University

Mikel Duke

Victoria University

Tzahi Y. Cath

Colorado School of Mines

Long D. Nghiem

University of Wollongong, longn@uow.edu.au

Follow this and additional works at: https://ro.uow.edu.au/eispapers

Part of the Engineering Commons, and the Science and Technology Studies Commons

Research Online is the open access institutional repository for the University of Wollongong. For further information contact the UOW Library: research-pubs@uow.edu.au 


\title{
Scaling control during membrane distillation of coal seam gas reverse osmosis brine
}

\author{
Abstract \\ We systematically assess the efficiency of chemical cleaning and report a simple but elegant approach to \\ control scaling during membrane distillation (MD) of brine from reverse osmosis (RO) treatment of coal \\ seam gas (CSG) produced water. Results reported here show that increased feed water salinity and the \\ permeation of $\mathrm{CO} 2$ from the feed solution resulted in only a small and gradual decrease in water flux. On \\ the other hand, the precipitation of sparingly soluble salts on the membrane at high water recovery $(>70 \%)$ \\ led to a significant flux decline. Among the three chemical cleaning agents investigated, a reverse \\ osmosis scale cleaning agent (denoted as MC3) was the most effective at restoring the water flux; \\ however, MC3 cleaning was not able to completely remove scale deposits from the membrane and \\ restore its surface hydrophobicity to the original value because of the complexation of scalants with CSG \\ RO brine. The remaining scalants (i.e., silicates) reduced the membrane surface hydrophobicity and could \\ possibly enhance concentration polarisation and act as seeding for further scale formation. Thus, a \\ gradual decrease in MD performance with respect to both water flux and salt leakage was observed after \\ each MC3 cleaning cycle. It was noted that the chemical cleaning agents themselves did not alter the \\ hydrophobicity of the membrane; thus, the gradual decline in MD performance was attributed to the \\ remaining scale deposits on the membrane after each cleaning cycle. Results reported here highlight the \\ need to prevent membrane scaling and only use chemical cleaning as the last resort during MD treatment \\ of CSG RO brine. Moreover, membrane scaling could be prevented by reducing concentration polarisation \\ via limiting feed temperature and thus water flux. MD treatment of CSG RO brine with up to $80 \%$ water \\ recovery without any observable membrane scaling was achieved at the feed temperature and the water \\ flux of $35^{\circ} \mathrm{C}$ and $10 \mathrm{~L} / \mathrm{m}^{2} \mathrm{~h}$, respectively. \\ Disciplines \\ Engineering | Science and Technology Studies \\ Publication Details \\ Duong, H. C., Gray, S., Duke, M., Cath, T. Y. \& Nghiem, L. D. (2015). Scaling control during membrane \\ distillation of coal seam gas reverse osmosis brine. Journal of Membrane Science, 493 673-682.
}

This journal article is available at Research Online: https://ro.uow.edu.au/eispapers/4240 


\title{
Scaling control during membrane distillation of coal seam gas reverse osmosis brine
}

\author{
Revised Manuscript Submitted to \\ Journal of Membrane Science
}

\begin{abstract}
Hung C. Duong ${ }^{1}$, Stephen Gray ${ }^{2}$, Mikel Duke ${ }^{2}$, Tzahi Y. Cath ${ }^{3}$, and Long D. Nghiem ${ }^{1, *}$
${ }^{1}$ Strategic Water Infrastructure Laboratory, School of Civil Mining and Environmental Engineering, University of Wollongong, Wollongong, NSW 2522, Australia

${ }^{2}$ Institute for Sustainability and Innovation, Victoria University, Australia

${ }^{3}$ Advanced Water Technology Center (AQWATEC), Department of Civil and Environmental Engineering, Colorado School of Mines, Golden, CO 80401, USA
\end{abstract}

* Corresponding author: Long Duc Nghiem, Email longn@uow.edu.au; Tel: +61 242214590 


\begin{abstract}
We systematically assess the efficiency of chemical cleaning and report a simple but elegant approach to control scaling during membrane distillation (MD) of brine from reverse osmosis (RO) treatment of coal seam gas (CSG) produced water. Results reported here show that increased feed water salinity and the permeation of $\mathrm{CO}_{2}$ from the feed solution resulted in only a small and gradual decrease in water flux. On the other hand, the precipitation of sparingly soluble salts on the membrane at high water recovery $(>70 \%)$ led to a significant flux decline. Among the three chemical cleaning agents investigated, a reverse osmosis scale cleaning agent (denoted as MC3) was the most effective at restoring the water flux; however, MC3 cleaning was not able to completely remove scale deposits from the membrane and restore its surface hydrophobicity to the original value because of the complexation of scalants with CSG RO brine. The remaining scalants (i.e., silicates) reduced the membrane surface hydrophobicity and could possibly enhance concentration polarisation and act as seeding for further scale formation. Thus, a gradual decrease in MD performance with respect to both water flux and salt leakage was observed after each MC3 cleaning cycle. It was noted that the chemical cleaning agents themselves did not alter the hydrophobicity of the membrane; thus, the gradual decline in MD performance was attributed to the remaining scale deposits on the membrane after each cleaning cycle. Results reported here highlight the need to prevent membrane scaling and only use chemical cleaning as the last resort during MD treatment of CSG RO brine. Moreover, membrane scaling could be prevented by reducing concentration polarisation via limiting feed temperature and thus water flux. MD treatment of CSG RO brine with up to $80 \%$ water recovery without any observable membrane scaling was achieved at the feed temperature and the water flux of $35{ }^{\circ} \mathrm{C}$ and $10 \mathrm{~L} / \mathrm{m}^{2}-\mathrm{h}$, respectively.
\end{abstract}

Keywords: Coal seam gas (CSG) produced water; brine management; membrane distillation (MD); scaling; chemical cleaning. 


\section{Introduction}

Coal seam gas (CSG), also known as coal seam methane or coal bed methane, is essentially methane gas trapped in coal seams together with ground water. During CSG production, both gas and water are extracted to the surface. Gas is commonly separated from water at the wellhead, and the remaining water is called CSG produced water [1]. CSG produced water is usually saline and dominated by sodium, bicarbonate, and chloride [2,3]. As a result, it is not suitable for direct environmental discharge or beneficial reuse $[2,4,5]$. In addition, the volume of water associated with CSG production can vary greatly from basin to basin and can be very large. For example, in Queensland, Australia, the yearly CSG produced water production is expected to be $100 \mathrm{GL}$ in 2015, and is predicted to reach maximum generation of $200 \mathrm{GL}$ in 2030 [1]. Therefore, costeffective and sustainable management of produced water is essential for the expansion of the CSG industry in Australia.

In most current CSG production projects in Australia, produced water is treated by reverse osmosis (RO) desalination prior to environmental discharge or beneficial reuse. However, RO can only achieve $75-80 \%$ water recovery [2, 6-8]. In Australia, where reinjection of CSG RO brine to depleted coal seams is generally not permitted, brine ponds have to be used as a temporary solution. Thus, new treatment technologies allowing for further water extraction and ultimately the extraction of minerals from CSG RO brine as saleable products are being investigated [9-12]. One such technology, membrane distillation (MD), which combines thermally driven distillation and membrane separation, has shown great promise for the treatment of hypersaline solutions, including CSG RO brine.

In $\mathrm{MD}$, a micro-porous hydrophobic membrane is used to separate the hot saline aqueous feed solution from the cold distillate and facilitate the transport of water vapour through its pores [1315]. Unlike the RO process, which is driven by a transmembrane hydraulic pressure difference, in MD a partial vapour pressure difference induced by a temperature gradient across the membrane is the driving force. Therefore, compared to RO, the water flux in MD is not affected to the same extent when the salinity of the feed solution (and thus its osmotic pressure) increases. As a result, a potential application of MD is arguably for the treatment of hypersaline solutions, and specifically the brine generated during RO desalination [10, 16-18].

A major technical challenge to the realisation of MD for CSG RO brine management is to control membrane scaling. The highly saline nature of produced water, particularly CSG RO brine, and the desire for high water recovery (i.e., the volume ratio of fresh water to feed water) can significantly elevate the risk of membrane scaling [19]. Membrane scaling can cause several negative consequences on MD performance, including flux reduction due to surface blockage, 
exacerbated temperature and concentration polarisation, salt leakage, and membrane damage [2023].

Given the significance of membrane scaling, there have been a large number of studies on membrane scaling and mitigation techniques in various MD configurations as summarised in recent review articles $[24,25]$. These studies have identified calcium carbonate, calcium sulphate, magnesium carbonate, and silicate as some of the most likely scalants during MD operation [24, 25]. In contrast to the large number of laboratory scale studies using synthetic saline feed, very few studies have attempted to examine the scaling potential of actual produced water. As a notable example, Thiel et al. [19] investigated the likely scalants in the treatment of produced water from Nova Scotia (Canada). In addition to calcium carbonate, calcium sulphate, magnesium carbonate, and silicate, the authors revealed that the precipitation of sodium chloride may also be a key factor that limits water recovery [19].

Several scaling mitigation approaches including chemical cleaning and process optimisation have been proposed and investigated [24]. However, none of them have been demonstrated for RO brine treatment. In addition, most of previous membrane scaling studies used synthetic feed water [23, 25-27]. Thus, the feasibility of chemical cleaning to control membrane scaling during MD treatment of CSG RO brine is still a subject of ongoing investigation. Using tap water as the feed, Gryta $[26,27]$ showed that calcium carbonate scaling developed in long-term operation and could be removed by a $2-5 \mathrm{wt} \% \mathrm{HCl}$ solution. Curcio et al. [23] investigated membrane fouling and scaling using synthetic seawater, and stated that membrane cleaning by citric acid followed by $\mathrm{NaOH}$ solution could restore most of the initial flux and the membrane hydrophobicity. Nghiem and Cath [20] investigated the scaling of direct contact membrane distillation (DCMD) using a synthetic saline solution containing calcium carbonate, calcium sulphate, and silicate. Membrane scaling caused by calcium sulphate was the most problematic, but could be effectively controlled by regularly flushing the feed channels with deionized water. Hickenbottom and Cath [17] proposed new scaling mitigation techniques called flow and temperature reversal. They successfully demonstrated their proposed techniques during DCMD of the Great Salt Lake water [17]. The techniques proposed by Nghiem and Cath [20] and Hickenbottom and Cath [17] are innovative; however, they involve frequent disruption to the process for rinsing and flow or temperature reversal. Thus, further development is required before their practical applications for scaling control can be realised.

Given the absence of viable membrane scaling mitigation techniques in the literature, and the high scaling propensity of CSG RO brine, this study aims to investigate the feasibility of DCMD for CSG RO brine treatment. Membrane scaling as well as the efficiency of membrane cleaning 
and their subsequent impacts on the DCMD process were systematically examined. A method to alleviate membrane scaling was then proposed and evaluated.

\section{Materials and methods}

\subsection{Materials}

\subsubsection{Lab-scale DCMD system}

A schematic diagram of the lab-scale DCMD system used in this study is shown in Fig. 1. The membrane cell was made of acrylic and composed of two semi-cells. Each semi-cell was engraved to create a flow channel with depth, width, and length of $0.3,9.5$, and $14.5 \mathrm{~cm}$, respectively. The active membrane area for mass transfer was $138 \mathrm{~cm}^{2}$. Two pumps (Model 120/IEC71-B14, Micropump Inc., Vancouver, Washington, USA) were used to circulate the feed and distillate through each semi-cell. The circulation flow rates were monitored using two rotameters.

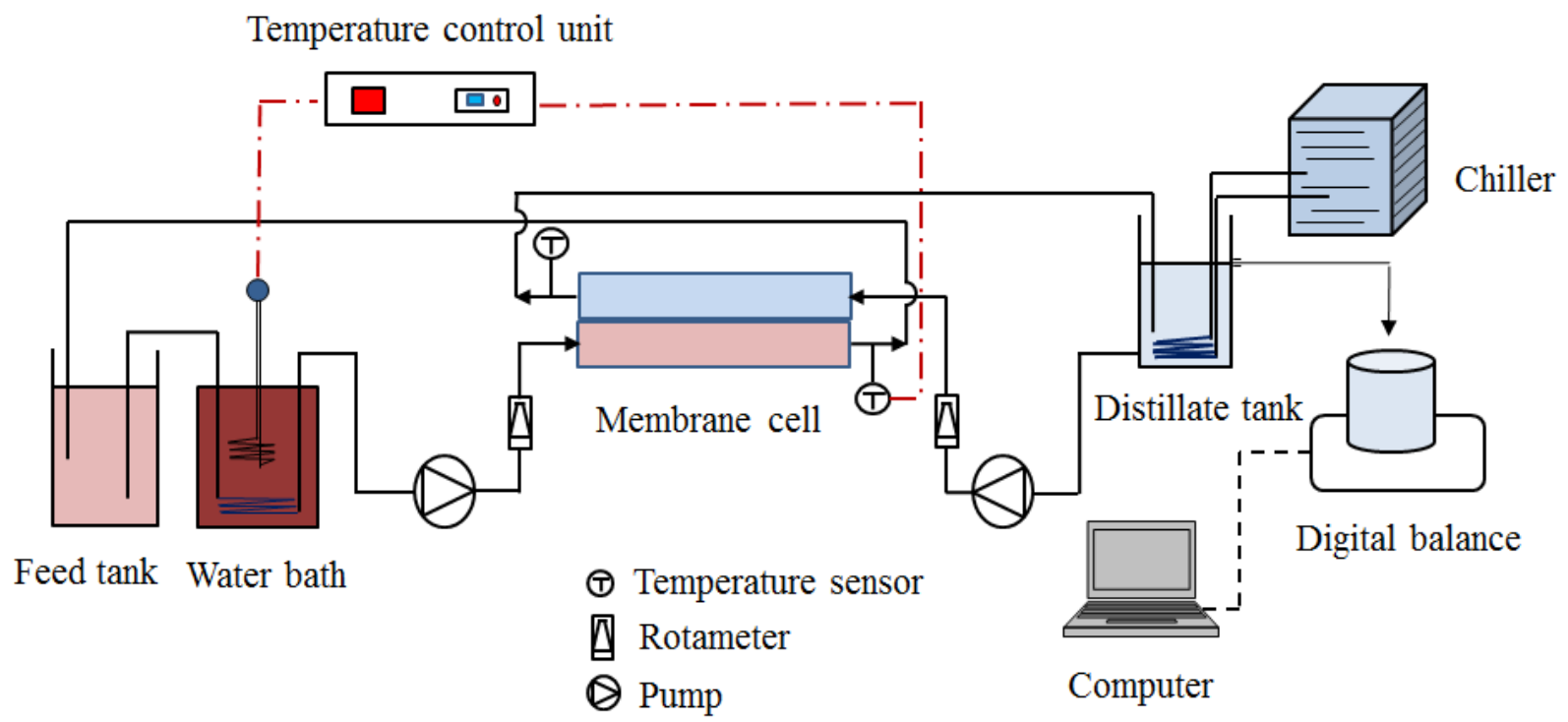

Fig. 1. Schematic diagram of the lab-scale DCMD system.

The feed solution was heated using a stainless steel heat-exchanging coil submerged in a hot water bath. A temperature sensor was placed immediately after the outlet of the feed channel. The water bath and the temperature sensor were connected to a temperature control unit to regulate the feed temperature. A digital balance (PB32002-S, Mettler Toledo, Inc., Hightstown, New Jersey, USA) connected to a computer was used to weigh the excess distillate flow for determining the water flux. A chiller (SC200-PC, Aqua Cooler, Sydney, New South Wales, 
Australia) was used to control the distillate temperature through a stainless steel heat-exchanging coil submerged directly into the distillate reservoir.

A flat-sheet membrane provided by Porous Membrane Technology (Ningbo, China) was used in this study. The membrane has a polypropylene (PP) supporting layer laminated with a $12 \mu \mathrm{m}-$ thick polytetrafluoroethylene (PTFE) active layer. The nominal pore size and porosity of this membrane were $0.2 \mu \mathrm{m}$ and $70 \%$, respectively.

\subsubsection{Saline solutions}

Three saline solutions, including CSG RO brine, synthetic CSG RO brine, and sodium chloride, were used. The CSG RO brine was from our previous pilot work at the Gloucester gas field (New South Wales, Australia). CSG produced water was pre-treated by ultrafiltration and then desalted by RO. Antiscalant (Osmotreat, Osmoflo, Adelaide, South Australia, Australia) was added to the $\mathrm{CSG}$ produced water prior to the RO treatment at a dose of $5 \mathrm{mg} / \mathrm{L}$. The water recovery of the pilot RO system was 75\%. Further details of this pilot study are available elsewhere [28]. Composition of major ions of the CSG RO brine is summarised in Table 1. The total dissolved solids (TDS), turbidity, and pH of this CSG RO brine were 17,100 mg/L, $0.22 \mathrm{NTU}$, and 8.2, respectively [28]. The synthetic solution was prepared from analytical grade sodium chloride and sodium bicarbonate to have the same bicarbonate/chloride mass ratio and TDS as the CSG RO brine from the Gloucester gas field. The $\mathrm{NaCl}$ solution was also prepared from the analytical grade chemical to have conductivity similar to that of the CSG RO brine $(22,300 \mu \mathrm{S} / \mathrm{cm})$.

Table 1. Composition of the CSG RO brine from the Gloucester gas field.

\begin{tabular}{lc}
\hline Ion & Concentration $(\mathbf{m g} / \mathbf{L})$ \\
\hline Sodium & 6,840 \\
\hline Chloride & 5,520 \\
\hline Bicarbonate & 4,740 \\
\hline Silica & 75 \\
\hline Potassium & 32 \\
\hline Magnesium & 17 \\
\hline Calcium & 14 \\
\hline
\end{tabular}

\subsubsection{Cleaning solutions}

Tap water, $0.5 \mathrm{wt} \% \mathrm{HCl}$, and $2.5 \mathrm{wt} \% \mathrm{MC} 3$ were used as membrane cleaning solutions. The 0.5 wt\% $\mathrm{HCl}$ solution was prepared using analytical grade $\mathrm{HCl}$ from VWR International Pty Ltd (Australia). The $2.5 \mathrm{wt} \% \mathrm{MC} 3$ solution was made from a commercial cleaning agent, Floclean MC3 (IMCD Australia Limited, Mulgrave, Victoria, Australia), following the manufacturer recommendations for $\mathrm{RO}$ membrane cleaning, resulting in a clear liquid at $\mathrm{pH} 3$. According to the 
manufacturer, Floclean MC3 had been designed specifically to clean RO membranes scaled by metal hydroxides, calcium carbonate, and similar deposits. In addition, there were no surfactants in Floclean MC3.

\subsection{Analytical methods}

\subsubsection{Contact angle measurement}

Water-membrane contact angle was used to determine the hydrophobicity of membrane. The contact angle measurements of the membranes were performed with a Rame-Hart Goniometer (Model 250, Rame-Hart, Netcong, New Jersey, USA) using the standard sessile drop method (i.e., with droplet volume of $12 \mu \mathrm{L}$ ). Membrane samples were gently washed with Milli-Q water and then air-dried prior to contact angle measurements. Milli-Q water was used as the reference liquid.

\subsubsection{Scanning electron microscope (SEM) and energy-dispersive X-ray spectroscopy (EDS) elemental analysis}

The morphology and composition of the surface of membranes were examined using a scanning electron microscope (Model JSM-6490LA, JEOL, Tokyo, Japan), with additional semiquantitative energy dispersive spectrometer. Prior to SEM analysis, the membrane samples were air-dried and subsequently sputtered with a thin layer of gold. SEM imaging was conducted at a voltage of $10 \mathrm{kV}$.

\subsubsection{Water quality parameters}

Electrical conductivity and $\mathrm{pH}$ of the feed and distillate were measured using an Orion 4-Star Plus pH/conductivity meter (Thermo Scientific, Waltham, Massachusetts, USA).

\subsection{Experimental protocols}

\subsubsection{DCMD experiments of saline solutions}

DCMD experiments with the $\mathrm{NaCl}$ solution, synthetic CSG RO brine, and CSG RO brine were performed under the same operating conditions. The process was started with $4 \mathrm{~L}$ of the saline solution in the feed tank and $2 \mathrm{~L}$ of Milli-Q water as the initial distillate (condensate). Unless otherwise stated, the feed water and the distillate at temperatures of 50 and $25{ }^{\circ} \mathrm{C}$, respectively, were introduced to their respective membrane semi-cells at flow rates of $1 \mathrm{~L} / \mathrm{min}$ (cross flow velocities of $0.06 \mathrm{~m} / \mathrm{s}$ ). The normalised flux, which is the ratio of the water flux at a given time to the initial flux, along with the system water recovery, $\mathrm{pH}$ and electrical conductivity of the feed 
and the distillate were regularly monitored. DCMD operation was terminated when a system water recovery of $80 \%$ had been achieved or the normalised flux had decreased to 0.2 .

Prior to all experiments, membrane integrity was verified for 2 hours by measuring the water flux at the standard operating conditions described above using tap water as the feed solution. The membrane sample would be used for the subsequent experiment if the obtained water flux was between 30 and $32 \mathrm{~L} / \mathrm{m}^{2}-\mathrm{h}$. Otherwise, another membrane sample would be used.

A set of DCMD experiments using CSG RO brine feed at a temperature of 40 and $35^{\circ} \mathrm{C}$ was also conducted. Except for the reduced feed temperature, all other operating conditions were as described above.

\subsubsection{Membrane cleaning experiments}

DCMD experiments with the CSG RO brine were conducted under the same operating conditions (i.e., feed temperature of $50^{\circ} \mathrm{C}$ ) mentioned above. When the DCMD system achieved water recovery of $80 \%$ or if the normalised flux decreased to below 0.2 , membrane cleaning was initiated. During membrane cleaning, the feed solution was replaced with $1 \mathrm{~L}$ of the cleaning solution. The cleaning solution was circulated through the feed channel at $2 \mathrm{~L} / \mathrm{min}$ (cross flow velocity of $0.12 \mathrm{~m} / \mathrm{s}$ ) for one hour at room temperature $\left(25^{\circ} \mathrm{C}\right)$. To avoid any hydraulic pressure differential across the membrane, Milli-Q water was circulated through the distillate channel at the same flow rate $(2 \mathrm{~L} / \mathrm{min})$. After membrane cleaning, the membrane was taken out, rinsed with tap water, and allowed to dry overnight. Subsequently, the DCMD experiment was resumed using the cleaned membrane and fresh CSG RO brine. After the last chemical cleaning cycle, the membrane was removed for subsequent SEM and contact angle analysis.

Additional membrane cleaning experiments were conducted to elucidate the impacts of chemical cleaning agents on the membrane hydrophobicity. Virgin membrane coupons were cleaned with 1 $\mathrm{L}$ of $0.5 \mathrm{wt} \% \mathrm{HCl}$ and $2.5 \mathrm{wt} \% \mathrm{MC} 3$ solution for 6,12 , and 18 hours under the same cleaning conditions applied to the scaled membrane. After chemical cleaning, the membrane coupons were rinsed with Milli-Q water and air-dried prior to contact angle measurements.

\section{Results and discussions}

\subsection{DCMD treatment of saline solutions}

As shown in Fig. 2, despite having the same salinity, the three investigated feed solutions exhibited notably different water flux profiles. The water flux only slightly declined when $\mathrm{NaCl}$ 
solution was used as the feed. The observed decline in normalised water flux from 1.0 to 0.9 (at $80 \%$ water recovery) could be attributed to the increase in viscosity [28] and the decrease in water activity of the feed solution as salinity increased from 17,100 to over $85,500 \mathrm{mg} / \mathrm{L} \mathrm{NaCl}$ $[13,14,29]$. The viscosity of $\mathrm{NaCl}$ solution increases from 0.70 to $0.75 \mathrm{cP}$ as the concentration rises from 17,100 to $85,500 \mathrm{mg} / \mathrm{L}$ [30]. It is important to note that this influence of viscosity and water activity on water flux during MD is much smaller than the influence imposed by the increase in osmotic pressure during RO [31].

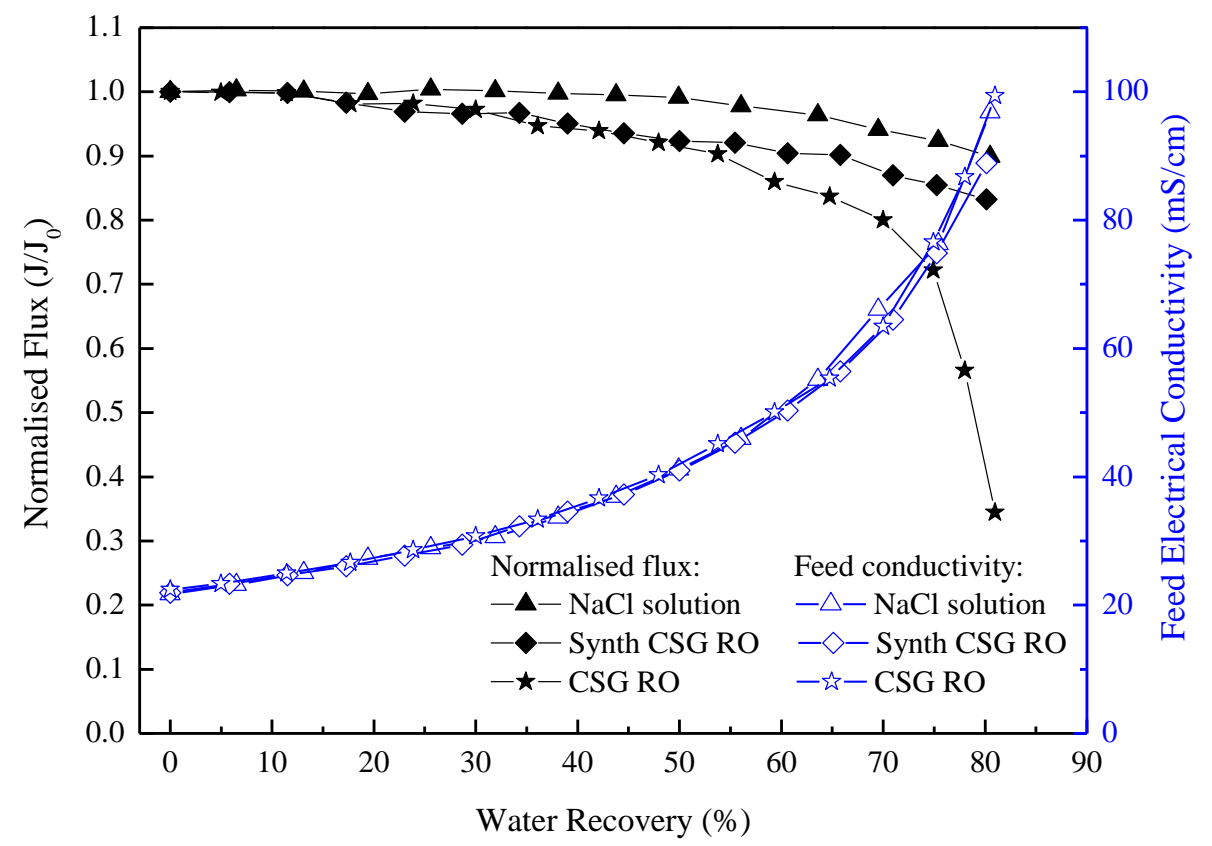

Fig. 2. Normalised flux and feed electrical conductivity versus water recovery in DCMD of $\mathrm{NaCl}$ solution, synthetic CSG RO brine, and CSG RO brine. Operating conditions: $\mathrm{T}_{\text {feed }}=50{ }^{\circ} \mathrm{C}$, $\mathrm{T}_{\text {distillate }}=25^{\circ} \mathrm{C}, \mathrm{V}_{\text {feed }}=\mathrm{V}_{\text {distillate }}=0.06 \mathrm{~m} / \mathrm{s}$. The initial water flux was from 30 to $32 \mathrm{~L} / \mathrm{m}^{2}-\mathrm{h}$.

Compared to the $\mathrm{NaCl}$ solution, water flux decline was slightly more significant when using the synthetic CSG RO brine as the feed to the DCMD process. The small additional flux decline associated with the synthetic CSG RO brine could be attributed to the migration of $\mathrm{CO}_{2}$ through the membrane pores, which could compete with the transport of water vapour $[20,24,28]$. As the feed water was heated, bicarbonate was reduced to $\mathrm{CO}_{2}\left(2 \mathrm{HCO}_{3}{ }^{-} \Leftrightarrow \mathrm{CO}_{3}^{2-}+\mathrm{CO}_{2}+\mathrm{H}_{2} \mathrm{O}\right)$ [32] At high temperature $\left(50{ }^{\circ} \mathrm{C}\right)$, the generated $\mathrm{CO}_{2}$ might be released from the hot feed solution and migrate through the membrane pores to the distillate [24]. The transport of $\mathrm{CO}_{2}$ through the membrane can be confirmed by the reduction in $\mathrm{pH}$ of the distillate at the early stage of the operation (Fig. 3). It is noteworthy that the solubility of $\mathrm{CO}_{2}$ in water is low and carbonic acid is 
a weak acid; thus, the decrease in the distillate $\mathrm{pH}$ could only be observed during the early stage of the DCMD experiments.

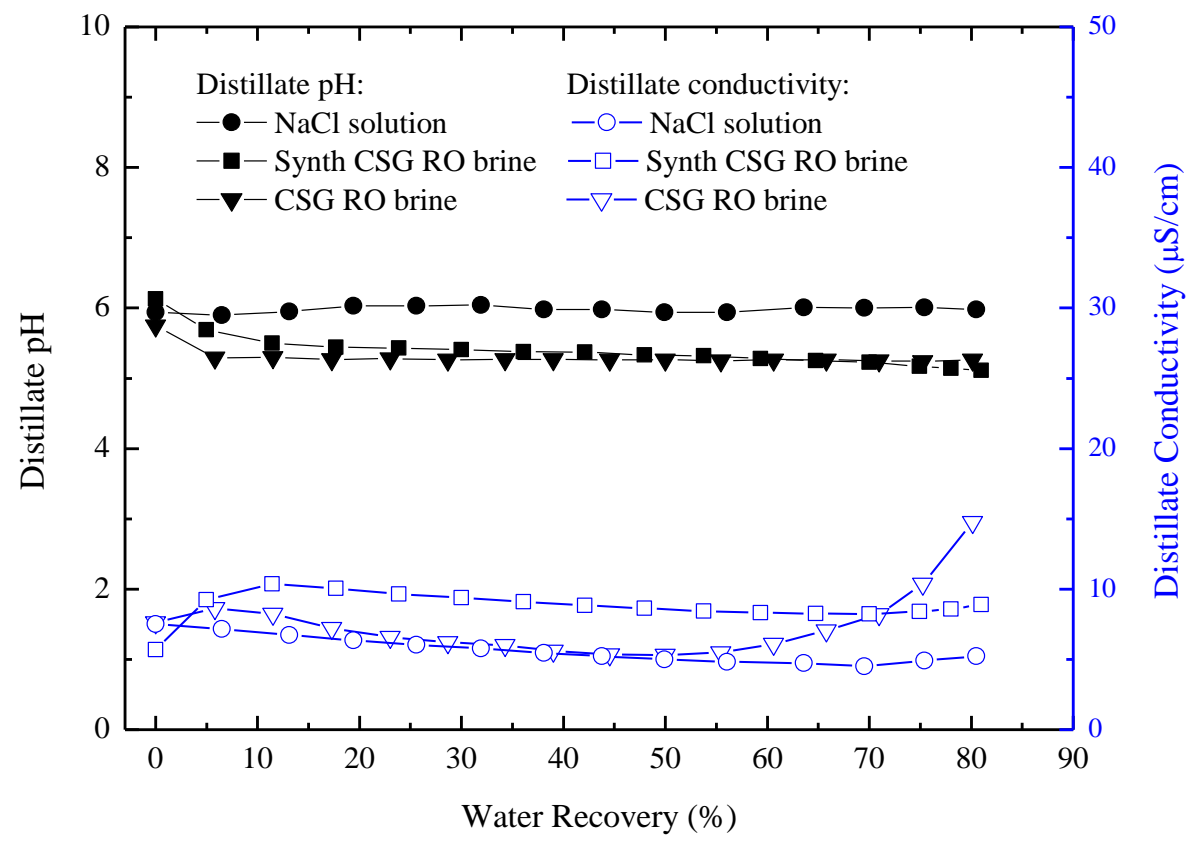

Fig. 3. $\mathrm{pH}$ and electrical conductivity of the distillate in DCMD of $\mathrm{NaCl}$ solution, synthetic CSG RO brine, and CSG RO brine. Operating conditions: $\mathrm{T}_{\text {feed }}=50^{\circ} \mathrm{C}, \mathrm{T}_{\text {distillate }}=25^{\circ} \mathrm{C}, \mathrm{V}_{\text {feed }}=$ $\mathrm{V}_{\text {distillate }}=0.06 \mathrm{~m} / \mathrm{s}$.

Significant flux decline was observed with the actual CSG RO brine. At low water recovery, the normalised flux was similar to those observed in the experiments with the synthetic CSG RO brine and $\mathrm{NaCl}$ solution. However, when water recovery exceeded $70 \%$, in addition to the permeation of $\mathrm{CO}_{2}$, the precipitation of sparingly soluble salts on the membrane surface led to a rapid flux decline. The normalised flux decreased to 0.3 when water recovery reached $80 \%$. SEM analysis of the membrane at the end of the experiment revealed a thick, amorphous layer of scale on the membrane surface. The scale layer increases both heat and mass transfer resistance through the membrane [21] and reduces its active area for water evaporation, thus reducing water flux. In addition, the increase in the distillate conductivity when water recovery exceeded $70 \%$ (Fig. 3) might be an indication of membrane pore wetting because of scaling. Membrane wetting contributes to the decrease in water flux as it also reduces the active membrane area.

Distillate of high quality was recovered from the three saline solutions (Fig. 3). The distillate conductivity remained stable and in the range of 5 to $10 \mu \mathrm{S} / \mathrm{cm}$ throughout the experiments with the synthetic CSG RO brine and the $\mathrm{NaCl}$ feed solutions. This confirms the absence of salt 
leakage and possible pore wetting during these experiments. During the DCMD experiments with the actual CSG RO brine, the formed scale might have partially wetted the membrane; however, the distillate conductivity was still below $15 \mu \mathrm{S} / \mathrm{cm}$.

\subsection{Membrane cleaning in DCMD treatment of CSG RO brine}

\subsubsection{Efficiency of various cleaning solutions}

Membrane cleaning efficiency can be evaluated based on the recovery of water flux and membrane surface hydrophobicity. Of the three cleaning solutions investigated in this study, the $2.5 \mathrm{wt} \%$ MC3 solution showed the best cleaning efficiency (Fig. 4). Following MC3 cleaning, nearly $100 \%$ of the initial flux was restored and the normalised flux remained stable above 0.85 at water recovery below $65 \%$, before sharply declining to 0.2 as water recovery reached $80 \%$. In contrast, only $85 \%$ and $90 \%$ initial water flux restoration was achieved after cleaning the scaled membrane with tap water and $0.5 \mathrm{wt} \% \mathrm{HCl}$, respectively. In addition, the normalised flux after membrane cleaning with tap water and $\mathrm{HCl}$ gradually decreased throughout the experiments. SEM analysis of the membranes also reveals that thick layers of scale remained on the membrane surface after tap water and $\mathrm{HCl}$ cleaning while only traces of scale were observed following MC3 cleaning (Fig. 4). The residual scale layer on the membrane worsened the intrinsic concentration polarisation of the MD process [21] and acted as nuclei for the precipitation of sparingly soluble salts, thus accelerating scale formation. As a result, the normalised flux started to gradually decrease at lower water recovery in the treatment of CSG RO brine following tap water and $\mathrm{HCl}$ cleaning.

The results obtained from qualitative elemental analysis of the membrane surface and scalants using SEM-EDS shown in Fig. 5 support the above discussion. The spectra of the virgin and scaled membranes (Fig. 5A and 5B) indicate that the scale layer formed by the end of the DCMD process of CSG RO brine was composed of mostly calcium and, to a lower extent, magnesium as well as silicate salts. The composition of the scale deposit did not change significantly after tap water cleaning (Fig. 5C). Cleaning the scaled membrane with $0.5 \mathrm{wt} \% \mathrm{HCl}$ effectively removed the alkaline (calcium and magnesium) scalants but it was less effective for silicate removal (Fig. 5D). A notable amount of silica was observed after $\mathrm{HCl}$ cleaning. The $2.5 \mathrm{wt} \% \mathrm{MC} 3$ solution demonstrated the best cleaning efficiency. However, traces of silica could still be seen in the EDS spectra (Fig. 5E). 

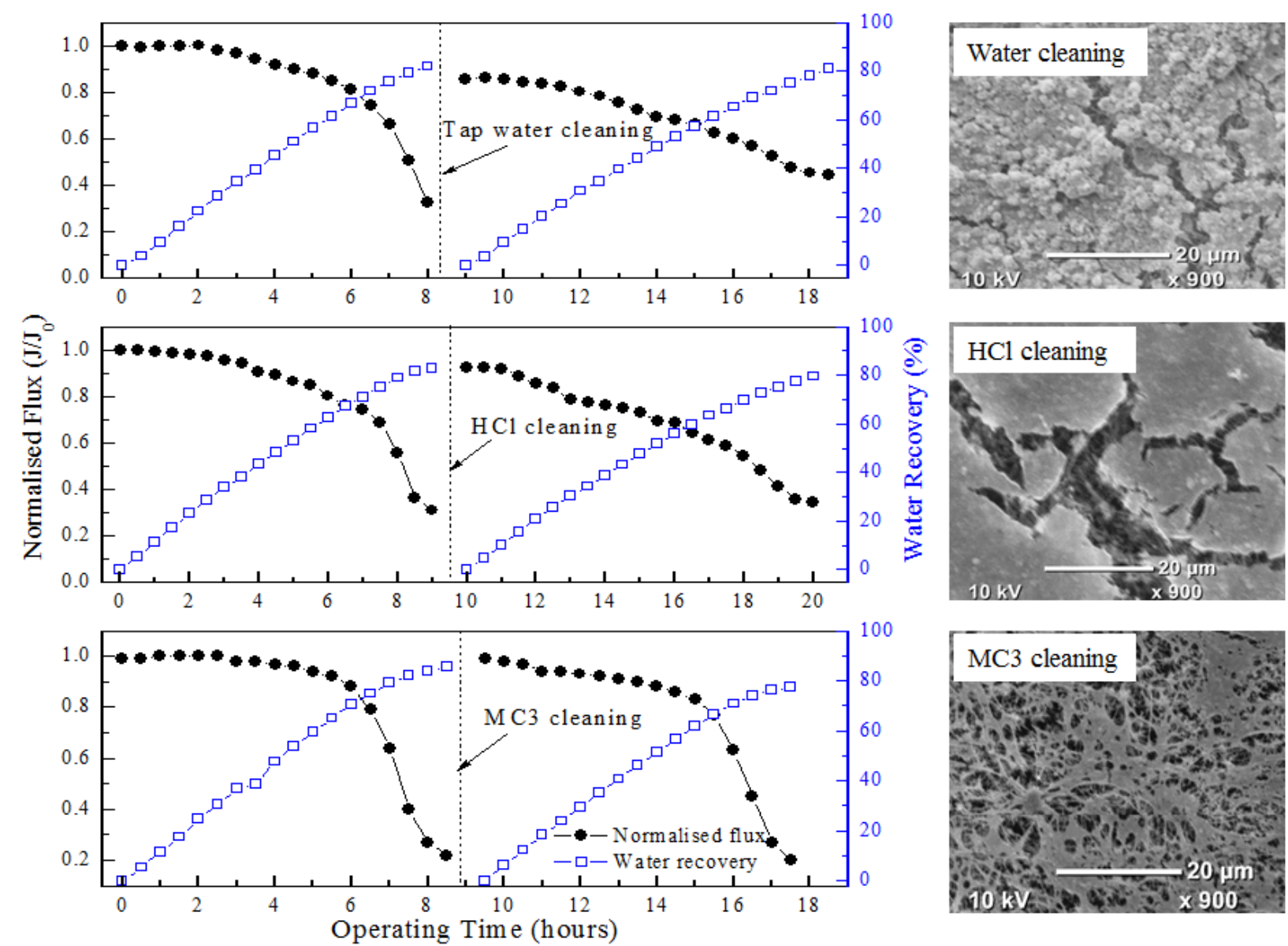

Fig. 4. Normalised flux and water recovery in DCMD of CSG RO brine prior and after membrane cleaning using tap water, $0.5 \mathrm{wt} \% \mathrm{HCl}$, and $2.5 \mathrm{wt} \% \mathrm{MC} 3$ solutions for 1 hour at room temperature and cross flow velocities of $0.12 \mathrm{~m} / \mathrm{s}$ and SEM photos of corresponding membranes after cleaning. DCMD operating conditions: $\mathrm{T}_{\text {feed }}=50^{\circ} \mathrm{C}, \mathrm{T}_{\text {distillate }}=25^{\circ} \mathrm{C}, \mathrm{V}_{\text {feed }}=$ $\mathrm{V}_{\text {distillate }}=0.06 \mathrm{~m} / \mathrm{s}$. The initial water flux was $30 \mathrm{~L} / \mathrm{m}^{2}-\mathrm{h}$. 

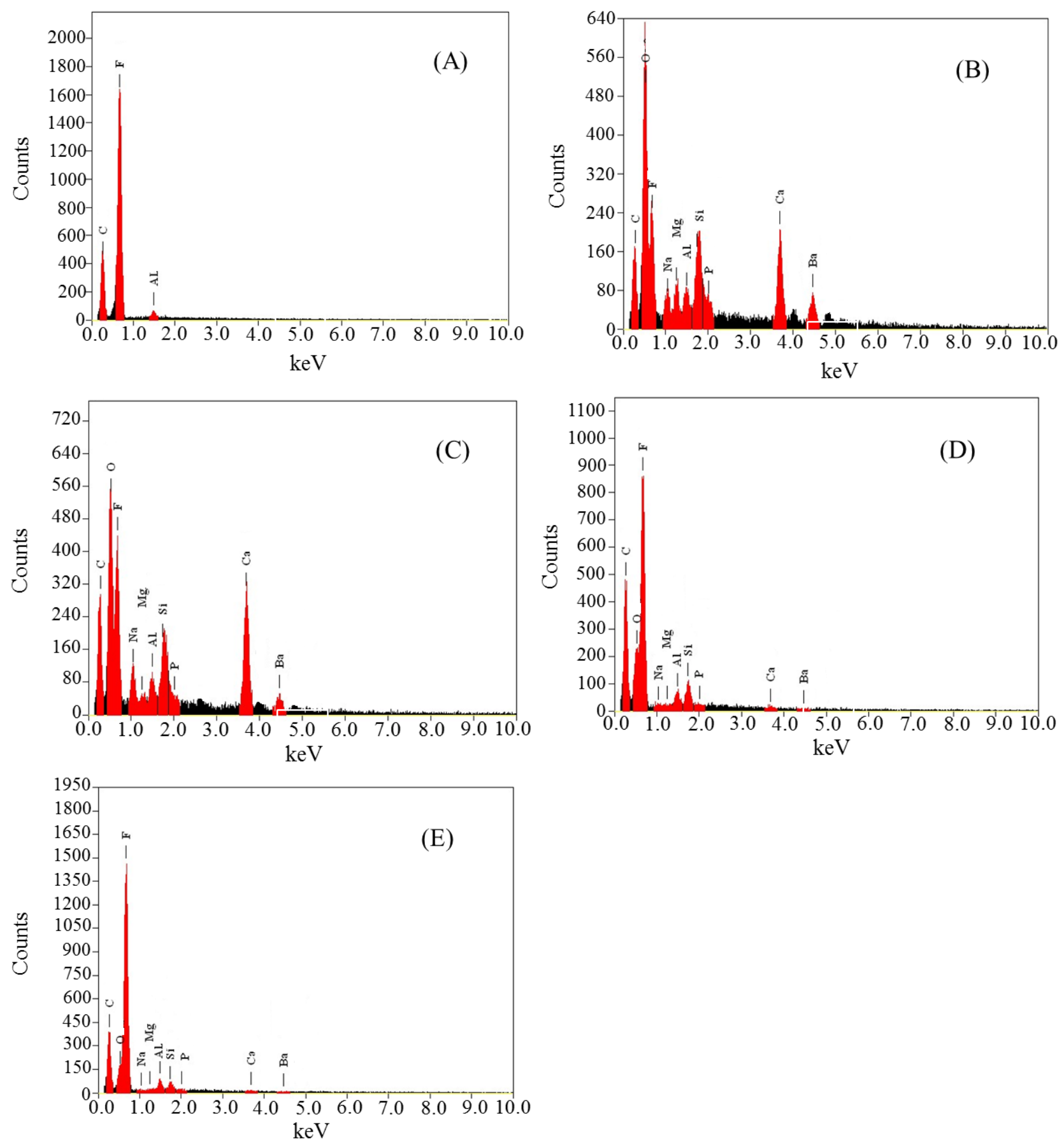

Fig. 5. EDS spectra of the surface of: (A) virgin membrane, (B) scaled membrane, and scaled membranes after cleaning with (C) tap water, (D) $0.5 \mathrm{wt} \% \mathrm{HCl}$ solution, and (E) $2.5 \mathrm{wt} \% \mathrm{MC} 3$ solution.

Contact angle measurements of the membranes also demonstrated the variations in the efficiency of the three cleaning solutions (Fig. 6). The virgin membrane had high contact angle (i.e., 133 ${ }^{\circ}$ ). After DCMD testing with tap water feed, the contact angle of the membrane slightly decreased to $126^{\circ}$. The slight reduction in membrane contact angle caused by tap water observed in this study was consistent with results reported by Ge et al. [33]. In contrast, a significant decrease in the 
membrane contact angle was observed at the end of the DCMD process with CSG RO brine. The severe precipitation of scale on the membrane surface reduced the contact angle to $50^{\circ}$. Cleaning the scaled membrane with tap water, $0.5 \mathrm{wt} \% \mathrm{HCl}$, and $2.5 \mathrm{wt} \% \mathrm{MC} 3$ solutions partially restored the contact angle to $66^{\circ}, 84^{\circ}$, and $98^{\circ}$, respectively. The contact angles of the membranes after chemical cleaning were lower than that of the virgin membrane. It is, however, noteworthy that no significant salt leakage was observed after one cycle of chemical cleaning, and the conductivity of the distillate was negligible (i.e., $<20 \mu \mathrm{S} / \mathrm{cm}$ ) in the DCMD experiment using the cleaned membranes.

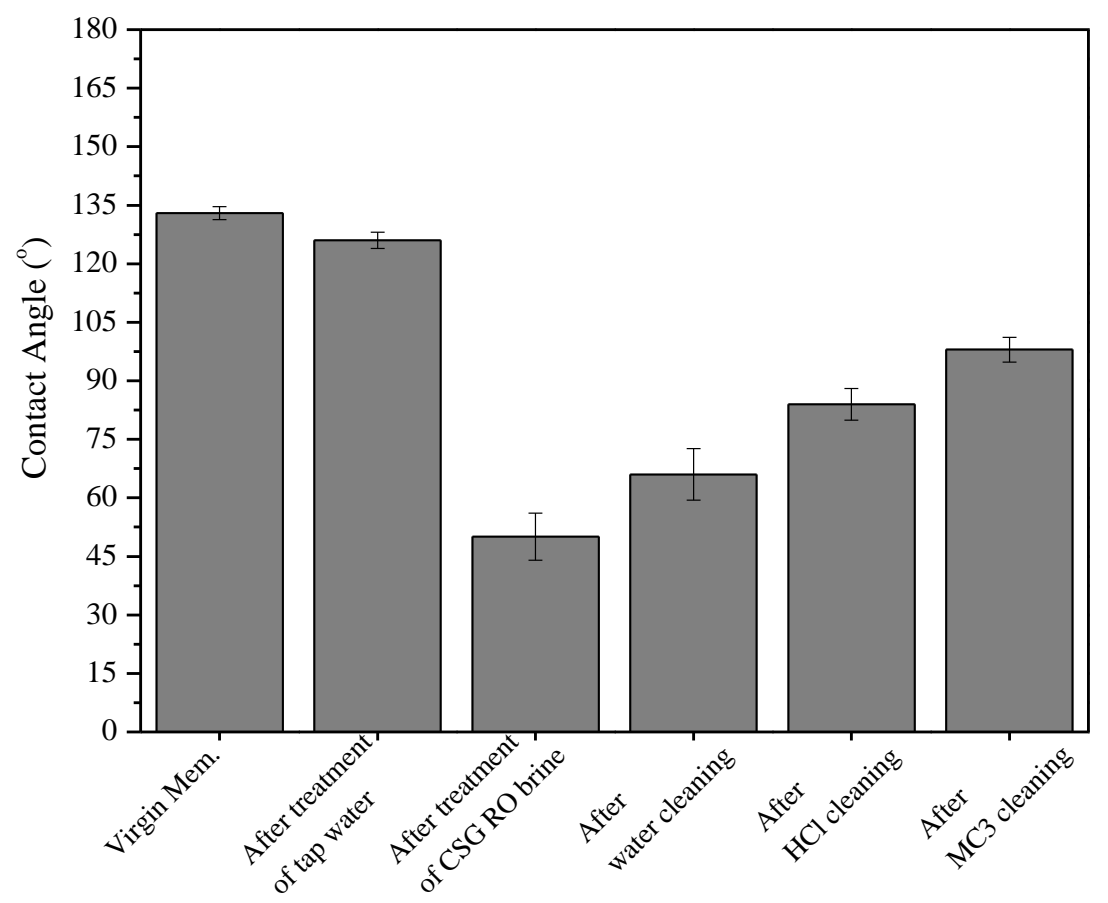

Fig. 6. Contact angles of: the virgin membrane, the membranes after DCMD of tap water and CSG RO brine, and the scaled membranes after cleaning with tap water, $0.5 \mathrm{wt} \% \mathrm{HCl}$, and 2.5 wt\% MC3 solutions. Milli-Q water was used as the reference. Error bars represent the standard deviation of 5 replicate measurements.

\subsubsection{Efficiency of repetitive membrane chemical cleaning}

Of the three investigated cleaning agents, the $2.5 \mathrm{wt} \% \mathrm{MC} 3$ solution showed the highest membrane cleaning efficiency. Thus, it was chosen to investigate the impacts of repetitive chemical cleaning on the performance of the DCMD membrane for desalination of CSG RO brine. Cleaning efficiency of the MC3 solution gradually decreased as the membrane cleaning cycles were repeated. Repetitive membrane cleaning (using fresh $2.5 \mathrm{wt} \%$ MC3 solution) resulted in a decrease in initial flux restoration (Fig. 7). After the first MC3 cleaning, nearly 100\% of the initial flux was restored, whereas a lower flux restoration (i.e., 95\%) was achieved from the 
second cleaning. Scale formation also occurred at lower water recovery in subsequent DCMD tests as membrane cleaning was repeated. Severe membrane scaling, indicated by rapid flux decline, was observed as water recovery exceeded $60 \%$ in the DCMD test after one MC3 cleaning cycle. In contrast, following the second MC3 cleaning the flux started to rapidly decline when only $50 \%$ of the RO brine had been recovered to the distillate.

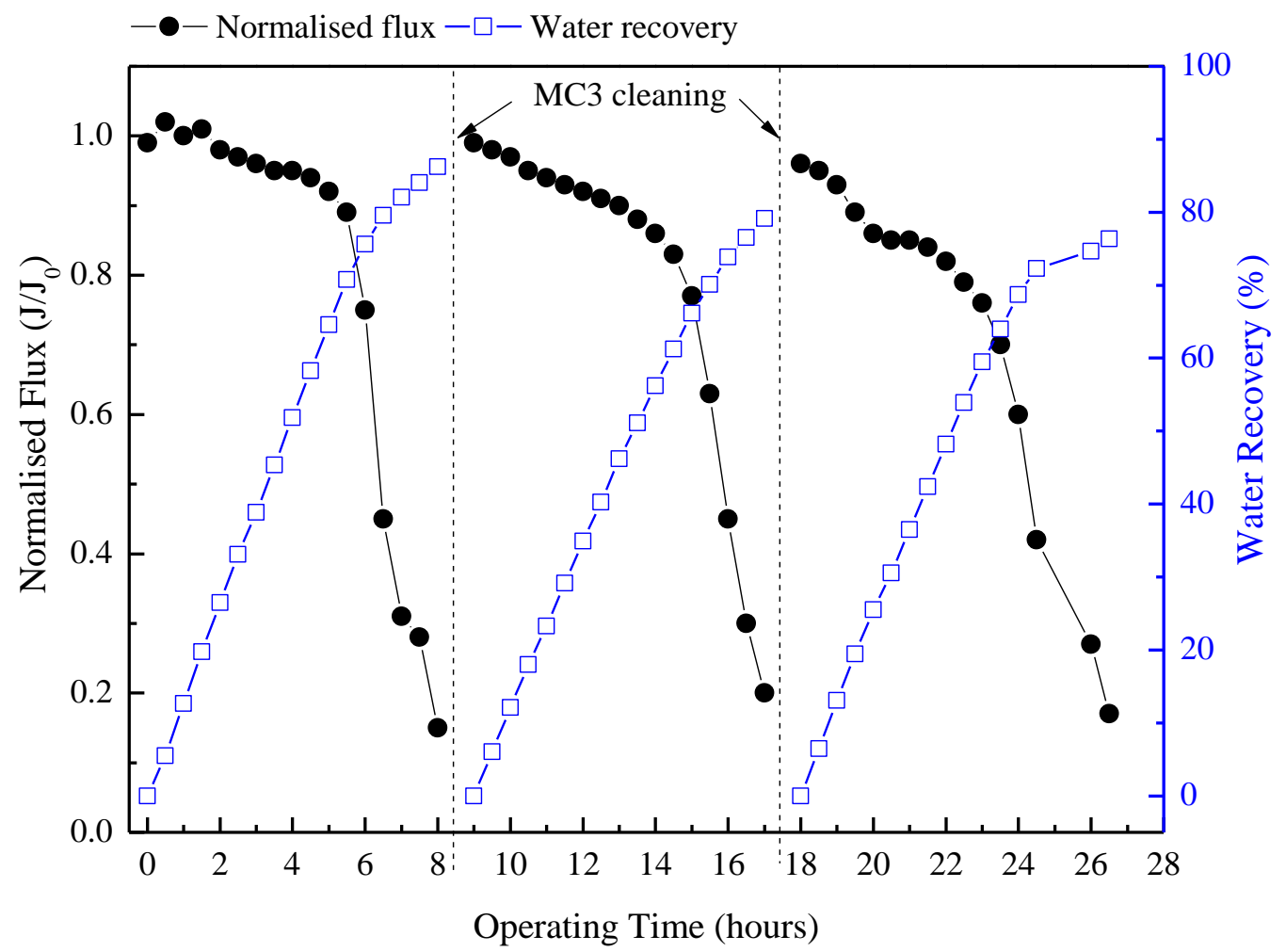

Fig. 7. Normalised flux and water recovery in the repetitive DCMD of CSG RO brine applying MC3 cleaning. Cleaning conditions: $1 \mathrm{~L}$ of $2.5 \mathrm{wt} \% \mathrm{MC} 3$ solution, room temperature, cross flow velocities $\mathrm{V}_{\text {feed }}=\mathrm{V}_{\text {distillate }}=1.2 \mathrm{~m} / \mathrm{s}$. DCMD operating conditions: $\mathrm{T}_{\text {feed }}=50^{\circ} \mathrm{C}, \mathrm{T}_{\text {distillate }}=25^{\circ} \mathrm{C}$, $\mathrm{V}_{\text {feed }}=\mathrm{V}_{\text {distillate }}=0.06 \mathrm{~m} / \mathrm{s}$. Initial water flux was $30 \mathrm{~L} / \mathrm{m}^{2}$-h.

The impact of repetitive MC3 cleaning on MD performance was also demonstrated by a gradual increase in salt leakage - the distillate conductivity increased gradually and decreased conductivity rejection was observed after each chemical cleaning cycle (Fig. 8). In the DCMD process of CSG RO brine using the virgin membrane and the scaled membrane after the first MC3 cleaning, distillate of high quality (electrical conductivity below $20 \mu \mathrm{S} / \mathrm{cm}$ ) and conductivity rejection of above $99.9 \%$ were obtained. However, following the second MC3 cleaning cycle, membrane pore wetting appeared to occur at the early stage of the experiment leading to distillate contamination. The distillate conductivity gradually increased from $10 \mu \mathrm{S} / \mathrm{cm}$ 
at the beginning to $110 \mu \mathrm{S} / \mathrm{cm}$ at the end of the experiment. As a result, the conductivity rejection of the system significantly decreased throughout the operation.

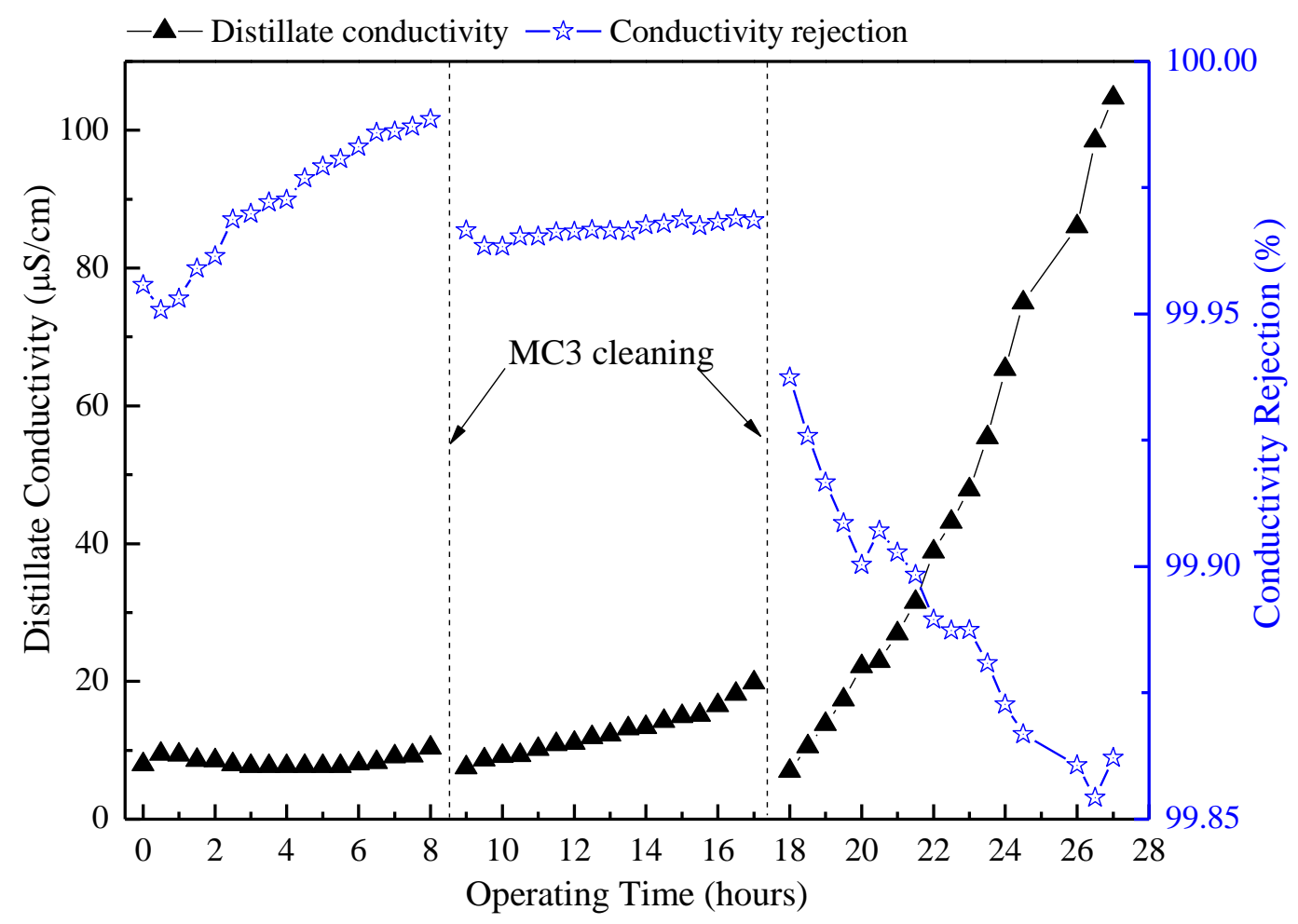

Fig. 8. Distillate conductivity and conductivity rejection in DCMD of CSG RO brine using the virgin membrane and the membrane after one and two MC3 cleaning cycles.

The decrease in efficiency of MC3 cleaning in the DCMD treatment of CSG RO brine might be attributed to the complexation of scalants with the feed water. Ion analysis of the CSG RO brine (Table 1) showed high concentrations of silica beside alkaline metals such as calcium and magnesium. The presence of calcium and magnesium was reported to catalyse the polymerisation of silica [34], thus accelerating silica deposition. The co-precipitation of silica and alkaline salts in the DCMD test of CSG RO brine was confirmed by the SEM-EDS analysis of the scale layer (Fig. 5B). It is widely accepted that a membrane scaled by silica is more difficult to be cleaned than if scaled by alkaline salts $[22,24]$. In addition, unlike alkaline scalants, which tend to deposit on the membrane surface, silica scaling was reported to deposit deeper into the membrane pores [22]. Therefore, a possible explanation for the decreased cleaning efficiency and MD performance upon repetitive cycling is the formation of scale inside the pores that hinders the efficiency of chemical cleaning, and results in pore wetting in repetitive membrane cleaning [25]. Furthermore, the acid based cleaning reagent MC3 was not designed for silica removal. Thus, 
silica scale can on the membrane surface causing a gradual decrease in water flux and membrane hydrophobicity decrease after repetitive cleaning.

It is noteworthy that the chemical cleaning agents used in this study did not exert any discernible impacts on the hydrophobicity of the PTFE membrane. The contact angles of the virgin membrane remained unchanged after being cleaned with the $0.5 \mathrm{wt} \% \mathrm{HCl}$ and $2.5 \mathrm{wt} \% \mathrm{MC} 3$ solutions for 6,12 , and 18 hours. The reported results indicate that the reduction in the membrane hydrophobicity observed in the repetitive DCMD testing was attributed to the remaining scalants on the membrane rather than the chemical cleaning agents.

\subsection{Membrane scaling control in the DCMD treatment of CSG RO brine}

Membrane scaling during DCMD of CSG RO brine at high water recovery was effectively mitigated by reducing feed temperature, and thus water flux (Fig. 9). When operating the system at feed temperature of $50{ }^{\circ} \mathrm{C}$ (initial water flux of $30 \mathrm{~L} / \mathrm{m}^{2}-\mathrm{h}$ ), severe membrane scaling occurred as water recovery exceeded $70 \%$, leading to a significant decline in normalised flux. At feed temperature of $40{ }^{\circ} \mathrm{C}$ (initial water flux of $20 \mathrm{~L} / \mathrm{m}^{2}-\mathrm{h}$ ), membrane scaling started at a higher water recovery and was less severe. The normalised flux decreased to 0.8 as water recovery approached $80 \%$. In contrast, no membrane scaling occurred and stable DCMD operation was achieved at feed temperature of $35^{\circ} \mathrm{C}$ (initial water flux of $10 \mathrm{~L} / \mathrm{m}^{2}-\mathrm{h}$ ). The normalised flux only slightly decreased to 0.9 when $80 \%$ water recovery was achieved.

SEM analysis of the membrane surface at the end of the experiments also confirmed the impacts of operating temperature and initial water flux on membrane scaling (Fig. 9). A compact and amorphous scale layer was formed on the membrane surface following testing with feed temperature of $50{ }^{\circ} \mathrm{C}$ while a layer of well-defined angular crystals was observed when feed temperature was $40^{\circ} \mathrm{C}$. In contrast, no scale deposition on the membrane could be observed after testing with feed temperature of $35^{\circ} \mathrm{C}$.

However, it is noteworthy that the calculated Langelier Saturation Index (LSI) of the DCMD feed solution at water recovery of $80 \%$ indicated high potential for scale formation at all three investigated operating feed temperatures. The LSIs of the feed solution at temperatures of 50, 40, and $35^{\circ} \mathrm{C}$ were $2.0,1.8$, and 1.7 , respectively. These results indicate potential calcium carbonate scaling formation even at feed temperature of $35{ }^{\circ} \mathrm{C}$. Nevertheless, no scale formation was observed at this temperature. As noted in section 2.2, the addition of antiscalant prior to RO desalination [28] of the CSG produced water might helped mitigate scale formation in the DCMD process of CSG RO brine at low feed temperature (i.e., $35^{\circ} \mathrm{C}$ ). In addition, as discussed in 
section 3.1, the transport of carbon dioxide through the membrane might also reduced the actual scaling potential of the system [20, 24, 28].

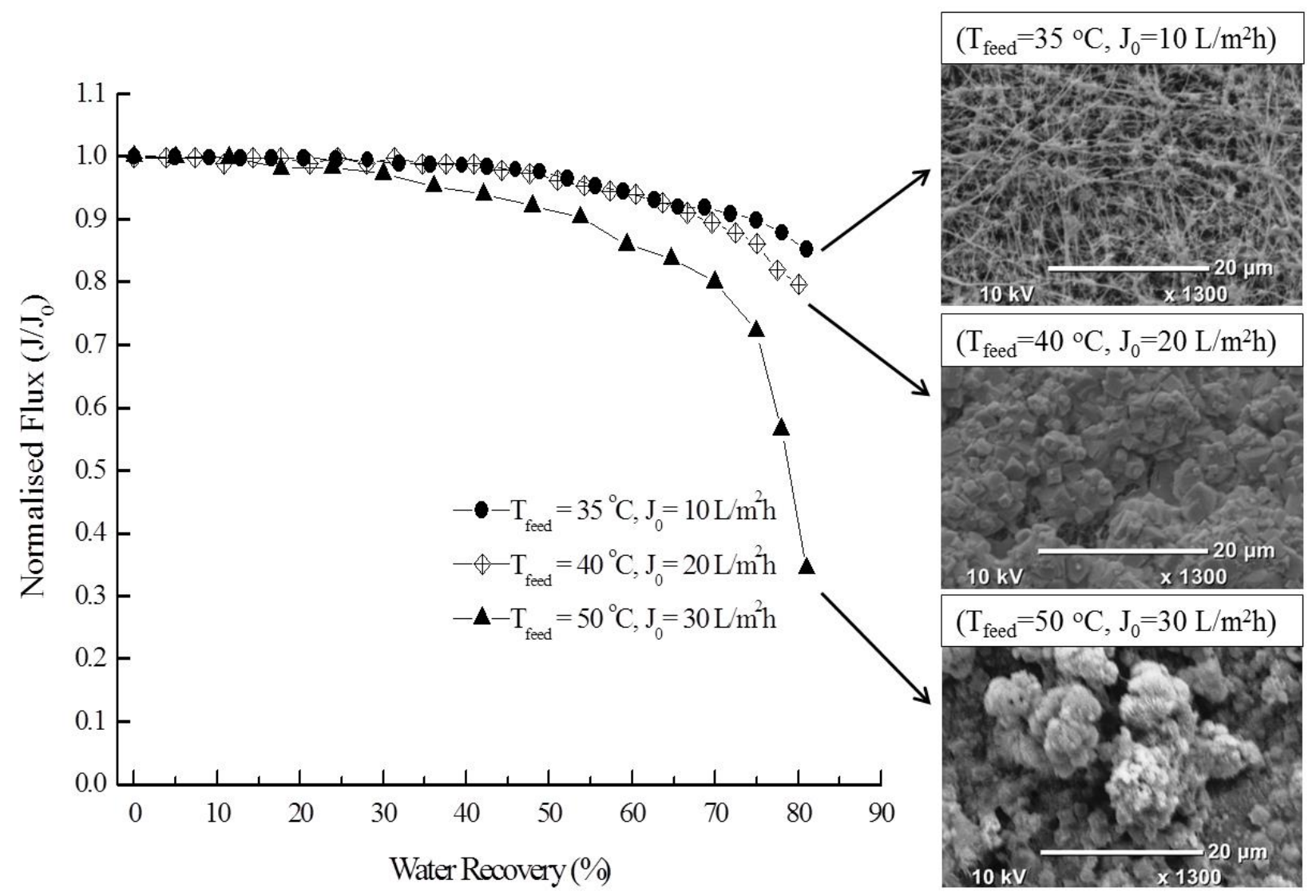

Fig. 9. Normalised flux versus water recovery and SEM photos of scaled membranes in the DCMD process of CSG RO brine operated at feed temperatures, $\mathrm{T}_{\text {feed }}$, of 35,40 , and $50{ }^{\circ} \mathrm{C}$ (corresponding to initial flux of $10,20,30 \mathrm{~L} / \mathrm{m}^{2}-\mathrm{h}$, respectively). Distillate temperature $\mathrm{T}_{\text {distillate }}=$ $25^{\circ} \mathrm{C}$, feed and distillate cross flow velocity $\mathrm{V}_{\text {feed }}=\mathrm{V}_{\text {distillate }}=0.06 \mathrm{~m} / \mathrm{s}$.

The difference in membrane scaling observed in the DCMD process of CSG RO brine at various operating conditions can be attributed to the extent of concentration polarisation at the membrane surface $[35,36]$. Due to concentration polarisation, the solute concentration immediately at the membrane surface can be higher than the bulk solute concentration [13] as expressed by Eq. (1):

$$
\frac{\mathrm{C}_{\mathrm{fm}}}{\mathrm{C}_{\mathrm{fb}}}=\exp \left(\frac{\mathrm{J}}{\rho \mathrm{K}}\right)
$$

where $\mathrm{C}_{\mathrm{fm}}$ and $\mathrm{C}_{\mathrm{fb}}$ are the solute concentration at the membrane surface and in bulk solution in the feed channel, respectively, $\mathrm{J}$ is the water flux, $\rho$ is the density of feed solution, and $\mathrm{K}$ is mass transfer coefficient. Given this relationship, an increase in the water flux results in an exponential increase in solute concentration at the membrane surface. As a result, operating DCMD of CSG RO brine at higher feed temperature and increased water flux led to more severe membrane 
scaling at the end of the experiments. Membrane scaling also started at a lower water recovery in DCMD experiments conducted with higher feed temperature and water flux [17].

The results reported here suggest that the precipitation of scale on the membrane surface can be mitigated by operating the system at low feed temperature and thus low water flux. The DCMD treatment of CSG RO brine at $80 \%$ water recovery without any observable membrane scaling was feasible at feed and distillate temperatures of 35 and $25^{\circ} \mathrm{C}$, respectively, corresponding to initial water flux of $10 \mathrm{~L} / \mathrm{m}^{2}-\mathrm{h}$. However, it is worth noting that lowering feed temperature, and hence water flux, reduces the thermal efficiency of the MD process [37-40] and increases the operation duration required for a specific initial brine volume. Thus, there exists a trade-off between membrane scaling prevention and economic efficiency in the MD treatment of CSG RO brine.

\section{Conclusions}

DCMD treatment of CSG RO brine for further fresh water extraction and brine minimisation was investigated. At high water recovery (i.e., >70\%), while increased feed salinity and the migration of $\mathrm{CO}_{2}$ through the membrane resulted in only a small decrease in water flux, the precipitation of sparingly soluble salts on the membrane significantly reduced the water flux. Membrane cleaning using $2.5 \mathrm{wt} \% \mathrm{MC} 3$ solution was the most effective at restoring the water flux and recovering the hydrophobicity of the membrane. However, due to the complex composition of the scalants with CSG RO brine, MC3 cleaning could not completely remove scale deposits (i.e., silicates) from the membrane and restore its surface hydrophobicity to the original value. The remaining scalants increased concentration polarisation, and thus the rate of subsequent scaling, and deteriorated the membrane surface hydrophobicity. As a result, a gradual decrease in MD performance with respect to both water flux and salt leakage was observed after repetitive chemical cleaning. It is noteworthy that the chemical cleaning agents themselves did not alter the hydrophobicity of the membrane; thus, the gradual decline in MD performance could be attributed to the remnants of scale deposits. Furthermore, by reducing concentration polarisation via lowering feed temperature and thus water flux, membrane scaling could be substantially alleviated, however, at the expense of lower thermal efficiency. Results reported here demonstrated that up to $80 \%$ water recovery from CSG RO brine could be achieved without any observable membrane scaling by limiting the feed temperature and thus the initial water flux to a sufficiently low value (i.e., $35^{\circ} \mathrm{C}$ and $10 \mathrm{~L} / \mathrm{m}^{2}-\mathrm{h}$, respectively). 


\section{Acknowledgments}

The authors acknowledge the financial support (Project Number 09117) of the National Centre of Excellence in Desalination Australia (which is funded by the Australian Government through the Water for the Future initiative) and AGL Energy Ltd.

\section{References}

[1] State of Queensland (Department of Natural Resources and Mines), Forecasting coal seam gas water production in Queensland's Surat and southern Bowen basins: Summary, 2012. 1-25.

[2] L.D. Nghiem, T. Ren, N. Aziz, I. Porter, and G. Regmi, Treatment of coal seam gas produced water for beneficial use in Australia: A review of best practices, Desalin. Water Treat. 32 (2011) 316-323.

[3] I. Hamawand, T. Yusaf, and S.G. Hamawand, Coal seam gas and associated water: A review paper, Renew. Sust. Energ. Rev. 22 (2013) 550-560.

[4] C.R. Johnston, G.F. Vance, and G.K. Ganjegunte, Irrigation with coalbed natural gas coproduced water, Agric. Water Manag. 95 (2008) 1243-1252.

[5] M.H. Plumlee, J.-F. Debroux, D. Taffler, J.W. Graydon, X. Mayer, K.G. Dahm, N.T. Hancock, K.L. Guerra, P. Xu, J.E. Drewes, and T.Y. Cath, Coalbed methane produced water screening tool for treatment technology and beneficial use, J. Unconv. Oil Gas Resour. 5 (2014) 22-34.

[6] P. Xu and J.E. Drewes, Viability of nanofiltration and ultra-low pressure reverse osmosis membranes for multi-beneficial use of methane produced water, Sep. Purif. Technol. 52 (2006) 67-76.

[7] S. Mondal and S.R. Wickramasinghe, Produced water treatment by nanofiltration and reverse osmosis membranes, J. Membr. Sci. 322 (2008) 162-170.

[8] J.E. Drewes, N.T. Hancock, K.L. Benko, K. Dahm, P. Xu, D. Heil, and T.Y. Cath, Treatment of coalbed methane produced water, Explor. Prod. Oil Gas Rev. 7 (2009) 126128.

[9] A. Simon, T. Fujioka, W.E. Price, and L.D. Nghiem, Sodium hydroxide production from sodium carbonate and bicarbonate solutions using membrane electrolysis: A feasibility study, Sep. Purif. Technol. 127 (2014) 70-76.

[10] A. Subramani and J.G. Jacangelo, Treatment technologies for reverse osmosis concentrate volume minimization: A review, Sep. Purif. Technol. 122 (2014) 472-489. 
[11] C. Forrestal, Z. Stoll, P. Xu, and Z.J. Ren, Microbial capacitive desalination for integrated organic matter and salt removal and energy production from unconventional natural gas produced water, Environ. Sci.: Water Res. Technol. 1 (2015) 47.

[12] L.D. Nghiem, C. Elters, A. Simon, T. Tatsuya, and W. Price, Coal seam gas produced water treatment by ultrafiltration, reverse osmosis and multi-effect distillation: A pilot study, Sep. Purif. Technol. 146 (2015) 94-100.

[13] A. Alkhudhiri, N. Darwish, and N. Hilal, Membrane distillation: A comprehensive review, Desalination 287 (2012) 2-18.

[14] K.W. Lawson and D.R. Lloyd, Membrane distillation, J. Membr. Sci. 124 (1997) 1-25.

[15] A.M. Alklaibi and N. Lior, Membrane-distillation desalination: Status and potential, Desalination 171 (2005) 111-131.

[16] J.-P. Mericq, S. Laborie, and C. Cabassud, Vacuum membrane distillation of seawater reverse osmosis brines, Water Res. 44 (2010) 5260-5273.

[17] K.L. Hickenbottom and T.Y. Cath, Sustainable operation of membrane distillation for enhancement of mineral recovery from hypersaline solutions, J. Membr. Sci. 454 (2014) 426-435.

[18] H. Geng, J. Wang, C. Zhang, P. Li, and H. Chang, High water recovery of RO brine using multi-stage air gap membrane distillation, Desalination 355 (2015) 178-185.

[19] G.P. Thiel, S.M. Zubair, and J.H. Lienhard V, An analysis of likely scalants in the treatment of produced water from Nova Scotia, Heat Transfer Eng. 36 (2015) 652-662, DOI: $10.1080 / 01457632.2015 .954923$.

[20] L.D. Nghiem and T. Cath, A scaling mitigation approach during direct contact membrane distillation, Sep. Purif. Technol. 80 (2011) 315-322.

[21] L. Wang, B. Li, X. Gao, Q. Wang, J. Lu, Y. Wang, and S. Wang, Study of membrane fouling in cross-flow vacuum membrane distillation, Sep. Purif. Technol. 122 (2014) 133143.

[22] J. Gilron, Y. Ladizansky, and E. Korin, Silica fouling in direct contact membrane distillation, Ind. Eng. Chem. Res. 52 (2013) 10521-10529.

[23] E. Curcio, X. Ji, G. Di Profio, A.O. Sulaiman, E. Fontananova, and E. Drioli, Membrane distillation operated at high seawater concentration factors: Role of the membrane on $\mathrm{CaCO}_{3}$ scaling in presence of humic acid, J. Membr. Sci. 346 (2010) 263-269.

[24] D.M. Warsinger, J. Swaminathan, E. Guillen-Burrieza, H.A. Arafat, and J.H. Lienhard V, Scaling and fouling in membrane distillation for desalination applications: A review, Desalination 356 (2014) 294-313. 
[25] L.D. Tijing, Y.C. Woo, J.-S. Choi, S. Lee, S.-H. Kim, and H.K. Shon, Fouling and its control in membrane distillation-A review, J. Membr. Sci. 475 (2015) 215-244.

[26] M. Gryta, Long-term performance of membrane distillation process, J. Membr. Sci. 265 (2005) 153-159.

[27] M. Gryta, Alkaline scaling in the membrane distillation process, Desalination 228 (2008) 128-134.

[28] H.C. Duong, A.R. Chivas, B. Nelemans, M. Duke, S. Gray, T.Y. Cath, and L.D. Nghiem, Treatment of RO brine from CSG produced water by spiral-wound air gap membrane distillation - A pilot study, Desalination 366 (2015) 121-129.

[29] L. Martínez, Comparison of membrane distillation performance using different feeds, Desalination 168 (2004) 359-365.

[30] H. Ozbek, Viscosity of aqueous sodium chloride solutions from $0-150^{\circ} \mathrm{C}$, American Chemical Society $29^{\text {th }}$ Southeast Regional Meeting, Tapa, FL, November 9-11, 1971.

[31] L.D. Nghiem, F. Hildinger, F.I. Hai, and T. Cath, Treatment of saline aqueous solutions using direct contact membrane distillation, Desalin. Water Treat. 32 (2011) 234-241.

[32] M. Gryta, Desalination of thermally softened water by membrane distillation process, Desalination 257 (2010) 30-35.

[33] J. Ge, Y. Peng, Z. Li, P. Chen, and S. Wang, Membrane fouling and wetting in a DCMD process for RO brine concentration, Desalination 344 (2014) 97-107.

[34] R. Sheikholeslami, I.S. Al-Mutaz, S. Tan, and S.D. Tan, Some aspects of silica polymerization and fouling and its pretreatment by sodium aluminate, lime and soda ash, Desalination 150 (2002) 85-92.

[35] F. He, J. Gilron, H. Lee, L. Song, and K.K. Sirkar, Potential for scaling by sparingly soluble salts in crossflow DCMD, J. Membr. Sci. 311 (2008) 68-80.

[36] C.R. Martinetti, A.E. Childress, and T.Y. Cath, High recovery of concentrated RO brines using forward osmosis and membrane distillation, J. Membr. Sci. 331 (2009) 31-39.

[37] S. Lin, N.Y. Yip, and M. Elimelech, Direct contact membrane distillation with heat recovery: Thermodynamic insights from module scale modeling, J. Membr. Sci. 453 (2014) 498-515.

[38] L. Martínez-Díez, F.J. Florido-Díaz, and M.I. Vázquez-González, Study of evaporation efficiency in membrane distillation, Desalination 126 (1999) 193-198.

[39] S. Al-Obaidani, E. Curcio, F. Macedonio, G. Di Profio, H. Al-Hinai, and E. Drioli, Potential of membrane distillation in seawater desalination: Thermal efficiency, sensitivity study and cost estimation, J. Membr. Sci. 323 (2008) 85-98. 
[40] M. Qtaishat, T. Matsuura, B. Kruczek, and M. Khayet, Heat and mass transfer analysis in direct contact membrane distillation, Desalination 219 (2008) 272-292. 